\title{
Análise de viabilidade técnico-financeira da aplicação do asfalto borracha em rodovias do Tocantins
}

O descarte de pneus nos últimos anos tem aumentado drasticamente. A reutilização de pneus inservíveis nas misturas asfálticas torna-se bastante vantajoso para o setor da pavimentação. A borracha de pneu incorporada à mistura produz um material durável, resistente e sustentável. Este trabalho visa analisar a caracterização mecânica e de viabilidade técnico-financeira a aplicação do asfalto borracha. A pesquisa tem como objetivo avaliar o desempenho mecânico de misturas asfálticas do tipo concreto asfáltico pré-misturado a quente, produzidas com asfalto convencional e modificado com borracha de pneu moído. A incorporação da borracha à mistura foi realizada através do processo seco. Para a avaliação das propriedades mecânicas, as misturas foram submetidas a ensaio de estabilidade e fluência Marshall. O estudo de viabilidade técnico financeiro foi realizado através do orçamento dos processos construtivos utilizando a tabela SICRO de custos rodoviários.

Palavras-chave: Mistura asfáltica; Processo seco; Asfalto borracha.

\section{Technical-financial feasibility analysis of rubber asphalt application in Tocantins highways}

Tire disposal in recent years has increased dramatically. The reuse of waste tires in asphalt mixtures is very advantageous for the paving industry. The tire rubber incorporated into the mix produces a durable, durable and sustainable material. This work aims to analyze the mechanical characterization and technical-financia feasibility of the application of rubber asphalt. The research aims to evaluate the mechanical performance of asphalt mixtures of hot pre-mixed asphalt concrete produced with conventional asphalt and modified with crushed tire rubber. Incorporation of the rubber into the mixture was carried out by the dry process. Fo the evaluation of mechanical properties, the mixtures were subjected to Marshall stability and creep test. The financial technical feasibility study was carried out through the budget of the construction processes using the SICRO road cost table.

Keywords: Asphalt mixture; Dry process; Rubber Asphalt.

Topic: Engenharia de Transportes

Reviewed anonymously in the process of blind peer.
Received: 05/04/2019

Approved: 13/07/2019
Gustavo Carvalho da Silva

Instituto Tocantinense Presidente Antônio Carlos, Brasil

http://lattes.cnpq.br/9077814316132066

carvalhocons6@gmail.com

\section{Flávio Vieira da Silva Júnior}

Instituto Tocantinense Presidente Antônio Carlos, Brasil

http://lattes.cnpq.br/2211436659738090

flaviovisiju@gmail.com
Referencing this:

SILVA, G. C.; SILVA JÚNIOR, F. V.. Análise de viabilidade técnicofinanceira da aplicação do asfalto borracha em rodovias do Tocantins. Engineering Sciences, v.7, n.2, p.69-76, 2019. DOI: http://doi.org/10.6008/CBPC2318-3055.2019.002.0008 


\section{INTRODUÇÃO}

Nos últimos anos, a frota de veículos no Brasil teve um crescimento significativo, e tal crescimento gera algumas problemáticas, como o aumento do tráfego de veículos na rodovia, e posteriormente, o aumento de patologias e o aumento do descarte de pneus inservíveis. A disposição final dos pneus representa um problema de difícil solução pois são objetos volumosos e devem ser descartados de maneira apropriada. O descarte em aterros se torna inviável, pois os pneus apresentam baixa compressibilidade e degradação muito lenta (CEMPRE, 2018).

De acordo com o SEST SENAT (2017), no Brasil, pelo menos 450 mil toneladas de pneus são descartadas por ano. Isso equivale a cerca de 90 milhões de unidades utilizadas em carros de passeio. Os pneus demoram cerca de 600 anos para se decomporem na natureza, e quando são descartados de forma irregular podem se tornar criadouros do mosquito Aedes aegypti, transmissor da dengue, do Zika vírus e da Chikungunya. Segundo a Reciclanip, o descarte correto evitou que mais de 3,7 milhões de toneladas de pneus fossem parar em lugares errados. No intuito de melhorar as propriedades mecânicas das misturas asfálticas e para reduzir o impacto ambiental, a incorporação da borracha de pneus em revestimentos asfálticos tem sido bastante estudada.

De acordo com Oda (2000), a incorporação da borracha de pneus em cimentos asfálticos traz várias vantagens, as principais são: Redução do envelhecimento: a borracha de pneus contém carbono e oxidantes, isto proporciona redução do envelhecimento por oxidação; Aumento da flexibilidade: a concentração de elastômeros na borracha de pneus proporciona uma mistura mais flexível do que as misturas convencionais; Aumento do ponto de amolecimento: a adição de borracha ao ligante faz com que o ponto de amolecimento aumente $17^{\circ} \mathrm{C}$ em relação ao ligante convencional, promovendo uma resistência maior ao acúmulo de deformação permanente nas trilhas de roda; e redução da susceptibilidade térmica: as misturas que utilizam ligante asfalto-borracha são mais resistentes a variações de temperatura, o seu desempenho em altas e baixas temperaturas é superior aos pavimentos construídos com misturas convencionais.

Existem dois métodos de incorporação da borracha nas misturas asfálticas. No processo úmido, a borracha é misturada ao ligante, modificando-o permanentemente. A transferência das características da borracha contribui aumentando a resistência a fadigas das misturas asfálticas ocorre neste processo. As propriedades químicas e físicas da borracha são incorporadas ao ligante convencional, promovendo a resistência a ação química de óleos e combustíveis e pode proporcionar a redução do envelhecimento do cimento asfáltico (ODA, 2000).

No processo seco, objetivo de estudo deste trabalho, neste processo a utilização do pó de pneu reciclado é incorporado ao agregado, funcionando, assim, como um aditivo. Pedaços sólidos de borracha são adicionados e substituem cerca de 5\% dos agregados (RPA, 1999 citado por SPECHT, 2004). A quantidade de borracha não pode exceder $2 \%$ para a camada de rolamento e $3 \%$ para a camada de ligação em relação ao peso total da mistura (BERTOLLO, 2002). 
Deste modo, o presente trabalho teve como objetivo realizar um estudo de viabilidade técnicofinanceira da aplicação do asfalto borracha nas rodovias do Estado do Tocantins, e tem como objetivos específicos: verificar a influência da adição de borrachas com diferentes granulometrias e porcentagens; identificar os fatores externos que influenciam no desempenho do asfalto borracha; avaliar o desempenho da mistura asfáltica com adição de borracha em comparação com as misturas asfálticas convencionais; realizar estudo financeiro comparativo entre a aplicação de asfalto borracha e revestimentos convencionais.

\section{METODOLOGIA}

O estudo é caracterizado como uma pesquisa do tipo experimental, realizada a partir de ensaios laboratoriais. A viabilidade técnica financeira foi avaliada através de ensaios em laboratórios e planilhas orçamentarias. $\mathrm{O}$ orçamento dos processos construtivos foi considerado através de composição de preços da SICRO (Sistema de Custos Rodoviários) do ano de 2018. Os ensaios deram origem a análise comparativa entre o asfalto modificado com borracha de pneu moído e o asfalto convencional. A borracha utilizada no trabalho é resultado do processo de recapagem de pneus, foram recolhidas em Porto Nacional (TO) e encaminhadas para o laboratório do ITPAC-Porto, onde foram ensaiadas.

Os materiais utilizados no desenvolvimento do trabalho foram: Cimento asfáltico de petróleo (CAP 50/70); Borracha de pneu moído; Agregado graúdo; e agregado miúdo. Foi escolhido o cimento asfáltico de petróleo (CAP 50/70) devido ao fato de ser o tipo de asfalto mais utilizado em pavimentos flexíveis. Os agregados utilizaram como referência a faixa 'C' do DNIT 031/2006-ES, que se refere à faixa granulométrica do material utilizado em capa de rolamento. De acordo com Bertollo (2002), o sistema genérico de adição de borracha utiliza curvas granulométricas densas onde as partículas de borracha são incorporadas com diâmetro máximo de $2 \mathrm{~mm}$ (\#10). Após a coleta da borracha de pneu proveniente do processo de recapagem foi realizado a retirada de impurezas.

\section{Caracterização dos agregados}

Os ensaios de caracterização de agregados realizados foram o de massa unitária, massa específica, índice de forma, abrasão Los Angeles, absorção e de granulometria. Para a realização do ensaio de massa unitária utilizou-se um recipiente, uma haste de ferro e uma balança. O recipiente vazio foi pesado para determinação de sua massa, logo após, foi preenchido com o agregado. Depois disto, utilizou-se a haste de metal para nivelar o agregado ao recipiente. Por fim, o material é pesado. Este ensaio foi realizado com os agregados graúdo e miúdo. Para determinação da massa específica foi realizado o ensaio previsto pela NBR 9937, onde se pesou 500g de água e 1000g de agregado. A água e o agregado foram cuidadosamente colocados no frasco Chapmam, e posteriormente, o frasco foi movimentado para eliminar as bolhas de ar do seu interior.

O ensaio de índice de forma foi realizado para avaliar a qualidade do agregado graúdo em relação à forma dos grãos, considerando que os agregados com grãos de forma cúbica, tida como forma ótima para agregados britados, terão índice próximo de 1. Os grãos lamelares apresentarão valores bem mais altos, 
sendo considerado aceitável o limite de 3.0 índice se baseia na medida da relação entre comprimento e a espessura dos grãos do agregado.

Foi realizado o ensaio de abrasão Los Angeles para determinar o desgaste sofrido pelo agregado. As amostras de agregado foram separadas de acordo com a graduação B especificada na norma DNER-ME 03598. A amostra foi colocada no equipamento com 11 esferas e foi submetida a 500 rotações. Após o término das rotações o material foi peneirado na peneira de número 1,7mm, o agregado retido foi levado a estufa e pesado. A abrasão Los Angeles é calculada pela fórmula $A_{n}=m_{n}-m_{n}^{\prime} / m_{n} \times 100$, em que: $A_{n}=$ abrasão Los Angeles da graduação $n ; n=$ graduação $(A, B, C, D, E, F$ ou $G)$ escolhida para o ensaio; $M_{n}=$ massa total da amostra seca, colocada na máquina; M’n=massa da amostra lavada e seca, após o ensaio.

Para o ensaio de absorção utilizou-se uma amostra de $1000 \mathrm{~g}$ de agregado. O material foi colocado submerso em água por $24 \mathrm{hrs}$ e lego após esse período foi pesado para se obter a sua massa úmida. O ensaio de granulometria foi realizado de acordo com a NBR 248. As amostras foram lavadas e secas, e colocadas na sequência de peneiras. As peneiras então, foram colocadas no agitador mecânico. Após peneirado, o material retido em cada peneira foi pesado.

\section{Caracterização da Borracha}

Para o trabalho foram utilizadas raspas de borrachas de pneus de recapagem. Na borracha fornecida, mostrada na figura 1, foi realizado o ensaio de granulometria. No Brasil a metodologia de dosagem mais utilizada é a de Marshall. Este método foi desenvolvido por Bruce G. Marshall. O método foi proposto para determinar a quantidade de ligante asfáltico que seria utilizado na composição das misturas betuminosas, utilizadas em serviços de pavimentação rodoviária (SPECHT, 2004).

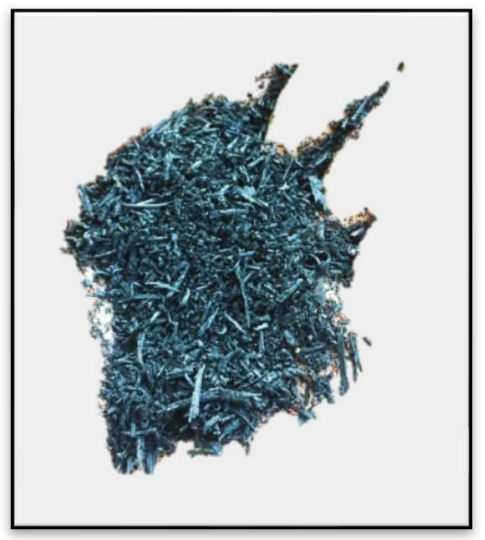

Figura 1: Borracha utilizada na pesquisa.

Neste trabalho, foram moldados corpos de prova com asfalto convencional e asfalto modificado com borracha. Os corpos de provas foram moldados variando a porcentagem de ligante utilizado. Foram moldados corpos de prova com 4,5\%, 5\%, 5,5\%,6\%, 6,5\% de ligante, para cada porcentagem foram produzidos 3 corpos de prova, como proposto nas figuras 2 e 3. Nos corpos de prova de asfalto borracha, a borracha de pneu substituiu $4 \%$ dos agregados de granulometria $0,42 \mathrm{~mm}$. 


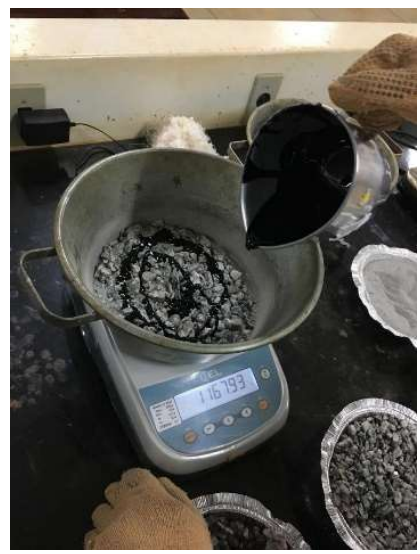

Figura 2: Dosagem do corpo de prova.

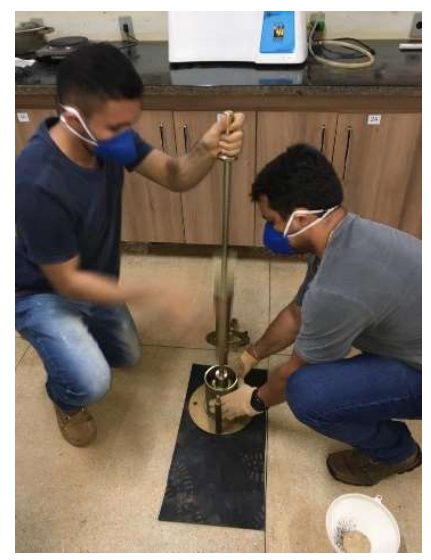

Figura 3: Compactação do corpo de prova.

\section{Ensaio de estabilidade Marshall}

Para ser verificado as propriedades dos corpos de prova foi realizado o ensaio de estabilidade Marshall. De acordo com a norma DNER-ME 043/95 a estabilidade é a resistência máxima à compressão radial apresentada pelo corpo de prova, em $\mathrm{N}$ (Kgf). O ensaio se iniciou quando os corpos de prova foram imersos em banho maria a uma temperatura de $60^{\circ} \mathrm{C}$ por um período de 30 a 40 minutos, em seguida o corpo de prova foi colocado em um molde de compressão, o molde então é colocado na prensa, após isso o corpo de prova é submetido a uma compressão diametral, aplicada por uma prensa. O valor de carga máxima suportada pelo corpo de prova é denominado estabilidade Marshall.

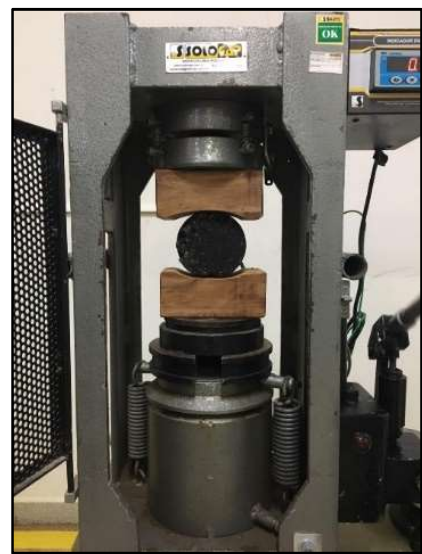

Figura 4: Ensaio de estabilidade Marshall.

\section{RESULTADOS E DISCUSSÃO}

\section{Caracterização dos agregados}

Para os ensaios de caracterização dos agregados foram obtidos os seguintes resultados apresentados quadro 1. Para o ensaio de abrasão Los Angeles, a granulometria do agregado utilizado foi a de graduação B, especificada na norma DENER-ME 081/98. Os resultados para esse ensaio são expressos pela fórmula $A n=5000-2530 / 5000 \times 1000$, sendo que $A n=49,4 \%$. A borracha utilizada no trabalho apresentou modulo de finura igual a 3,94 e sua dimensão máxima característica de 0,42 mm. Para a realização da pesquisa a borracha foi utilizada substituindo $4 \%$ do agregado miúdo desta mesma granulometria $(0,42 \mathrm{~mm})$. Propõe-se o quadro 2. 
Quadro 1: Caracterização dos agregados.

\begin{tabular}{|c|c|c|c|c|c|c|}
\hline Agregado (Tipo) & $\begin{array}{c}\text { Massa especifica } \\
\left(\mathbf{g} / \mathbf{c m}^{\mathbf{3}}\right)\end{array}$ & $\begin{array}{c}\text { Massa unitária } \\
\left(\mathbf{k g} / \mathbf{d m}^{\mathbf{3}}\right)\end{array}$ & $\begin{array}{c}\text { Dimensão máxima } \\
\text { caracteristica }(\mathbf{m m})\end{array}$ & Módulo de finura & Indice de forma & Absorção \\
\hline Brita 0 & 2,636 & 1,34 & 6,3 & 6,22 & 3,11 \\
\hline Brita1 & 2,633 & 1,377 & 12,5 & 7,07 & 3,32 \\
\hline Pó de brita & 2,688 & 1,562 & 0,42 & 2,94 & - \\
\hline
\end{tabular}

Quadro 2: Análise granulométrica da borracha.

\begin{tabular}{|c|c|c|}
\hline Peneira & \multicolumn{2}{|c|}{ Percentagem retida em massa (\%) } \\
\hline № & $\mathrm{mm}$ & Borracha \\
\hline $3 / 8^{\prime \prime}$ & 9,5 & 1,25 \\
\hline 4 & 4,75 & 26,55 \\
\hline 10 & 2,00 & 27,82 \\
\hline 40 & 0,42 & 40,00 \\
\hline 80 & 0,18 & 3,93 \\
\hline 200 & 0,074 & 0,38 \\
\hline
\end{tabular}

\section{Ensaio de estabilidade Marshall}

O ensaio de estabilidade Marshall foi realizado de acordo prescrito na norma DNER - 43/95. Após a desmoldagem dos corpos de prova, eles foram colocados em banho-maria a uma temperatura de $60^{\circ} \mathrm{C}$ por um período de 30 a 40 minutos (figura 5), e a seguir foram submetidos ao ensaio de compressão diametral para determinação da estabilidade.

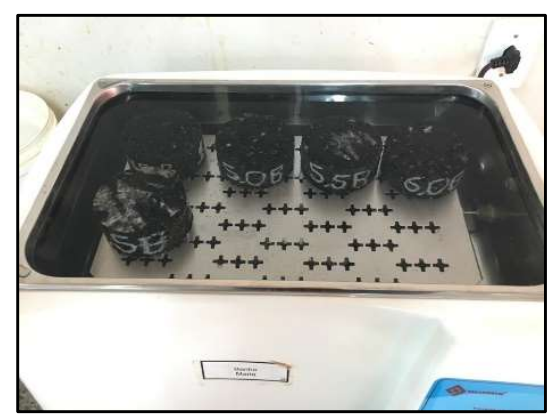

Figura 5: Corpos-de-prova em banho-maria.

A estabilidade é a resistência máxima apresentada pelo corpo-de-prova; os valores de estabilidade foram corrigidos em função da altura do corpo-de-prova. Vale ressaltar que o ensaio Marshall, mesmo sendo questionado por que as tensões que ocorrem durante a determinação da estabilidade são de difícil interpretação, por apresentar uma elevada dispersão de resultados e pela falta de correlação com o desempenho em campo, ainda é uma referência no Brasil (BERTOLLO, 2006).

No gráfico 1, está representado os valores obtidos nos ensaios. Não foi possível determinar a estabilidade Marshall para os corpos de prova de asfalto borracha, devido à dificuldade de agregação da borracha utilizada na pesquisa ao agregado, ocasionando assim um esfarelamento dos corpos de prova. A figura 6 mostra um corpo de prova com baixa agregação da borracha.

O projeto das misturas asfáltica convencional e com incorporação de borracha de pneu, deu-se a partir dos parâmetros Marshall, determinando o teor de ligante, atendendo os critérios de maior estabilidade, máxima densidade aparente e intervalo de volume de vazios (DIAS, 2005). Foram moldadas 3 
amostras cilíndricas para cada teor de ligante asfáltico. A dosagem Marshall resultou em um teor ótimo de ligante de 5,765\%, o resultado é apresentado no gráfico 2 e no quadro 3.

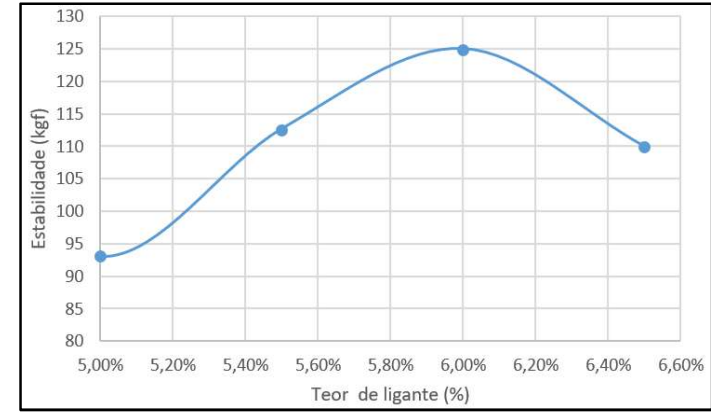

Gráfico 1: Estabilidade Marshall.

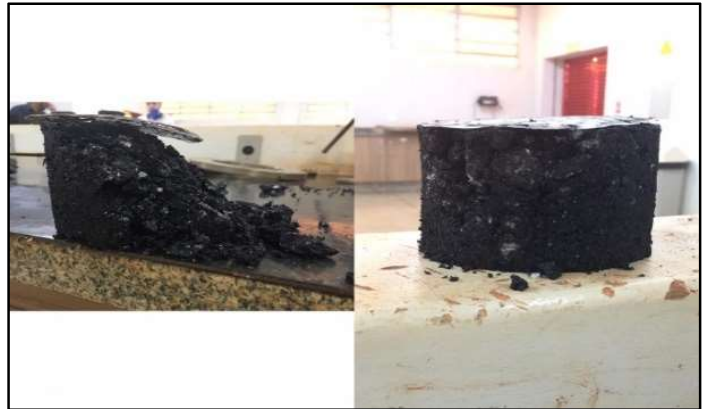

Figura 6: Corpo de prova de asfalto-borracha.

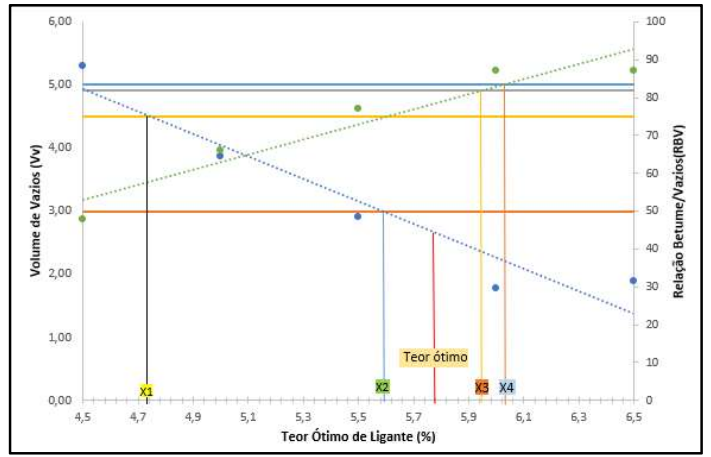

Gráfico 2: Determinação do teor ótimo de ligante.

Quadro 3: Determinação do teor ótimo de ligante.

\begin{tabular}{|c|c|c|}
\hline Teores & Valores (\%) & Teor Ótimo \\
\hline $\mathbf{X 1}$ & 4,72 & \multirow{2}{*}{5,765} \\
\hline $\mathbf{X 2}$ & 5,61 & \\
\hline $\mathbf{X 3}$ & 5,92 & \\
\hline $\mathbf{X 4}$ & 5,95 & \\
\hline
\end{tabular}

\section{Análise financeira}

A seguir, é representada, de maneira suscinta, a análise de custo de uma obra de um trecho de $1 \mathrm{~km}$ de extensão que utiliza uma camada de concreto asfáltico com ligante CAP-50/70 de $7 \mathrm{~cm}$ de espessura. Alternativamente, apresentamos também, o orçamento de um revestimento com asfalto borracha com a mesma espessura. De maneira didática prossegue a avaliação. Portanto, para $1 \mathrm{~km}$, se obtém as seguintes quantidades de massa asfáltica conforme demostrado no quadro 4. Premissas adotadas: 0 teor da mistura asfáltica com CAP 50/70 considerado é de 5,0 \%; e os preços por tonelada que remuneram todos os insumos e a aplicação da massa na pista, de forma expedita, são as expressas no quadro 5.

Quadro 4: Comparativo revestimento CBUQ Convencional X revestimento CBUQ com asfalto-borracha.

\begin{tabular}{|c|c|}
\hline Revestimento em CBUQ convencional & Revestimento em CBUQ com Asfalto-Borracha \\
\hline $\begin{array}{c}1000 \mathrm{~m} \times 7 \mathrm{~m} \times 0,07 \mathrm{~m} \times 2500 \mathrm{t} / \mathrm{m}^{3}=1225 \text { toneladas de } \\
\text { massa asfáltica de CBUQ normal }\end{array}$ & $\begin{array}{c}1000 \mathrm{~m} \times 7 \mathrm{~m} \times 0,07 \mathrm{~m} \times 2500 \mathrm{t} / \mathrm{m}^{3}=1225 \text { toneladas de massa } \\
\text { asfáltica de CBUQ com Asfalto-Borracha }\end{array}$ \\
\hline
\end{tabular}

Quadro 5: Comparativo revestimento CBUQ Convencional X revestimento CBUQ com asfalto-borracha.

\begin{tabular}{|c|c|}
\hline CBUQ com CAP 50/70 & CBUQ com Asfalto-Borracha \\
\hline $\mathrm{R} \$ 129,82 / \mathrm{t}$ & $\mathrm{R} \$ 155,9 / \mathrm{t}$ \\
\hline
\end{tabular}

Conforme se observa no quadro 3, o preço de execução do Asfalto-Borracha é $17 \%$ mais caro que o preço de execução de CBUQ convencional. Considerando os dados já mencionados, segue a descrição dos 
custos de execução dos revestimentos de CBUQ com cada tipo de asfalto. No que diz respeito a custos de implantação, o asfalto-borracha acaba tendo um custo maior, mas levando em consideração suas características de redução do envelhecimento, aumento da flexibilidade, aumento do ponto de amolecimento e redução da susceptibilidade térmica, o asfalto borracha se torna mais viável a longo prazo, pois os custos com reparo e manutenção serão menores se comparados ao asfalto convencional.

Quadro 6: Comparativo revestimento CBUQ Convencional X revestimento CBUQ com asfalto-borracha.

\begin{tabular}{|c|c|c|c|c|c|}
\hline \multirow{2}{*}{\multicolumn{2}{|c|}{ Grandezas }} & \multirow{2}{*}{ Cálculo } & \multirow{2}{*}{ Unidade } & \multicolumn{2}{|c|}{ Tipo de Asfalto } \\
\hline & & & & Convencional & Asfalto Borracha \\
\hline A & $\begin{array}{c}\text { Quantidade de massa } \\
\text { asfaltica }\end{array}$ & - & ton & 1125 & 1125 \\
\hline$B$ & Custo de usinagem & - & $\mathrm{R} \$ / \mathrm{t}$ & 129,82 & 155,9 \\
\hline C & Massa $\times$ Custo & $A \times B$ & $\mathrm{R} \$$ & 146047,5 & 175387,5 \\
\hline$D$ & Custo Total & - & RS & 146047,5 & 175387,5 \\
\hline
\end{tabular}

\section{CONCLUSÕES}

Através dos estudos realizados nesta pesquisa, pode-se evidenciar que o uso do asfalto borracha é viável em todos os aspectos abordados, sendo eles ambientais, econômicos, técnico e financeiro. Do ponto de vista econômico, pode-se verificar que o asfalto borracha tem um custo de implantação superior ao asfalto convencional, mas se levada em consideração a suas características de redução do envelhecimento, aumento da flexibilidade, aumento do ponto de amolecimento e redução da susceptibilidade térmica, o asfalto borracha torna-se economicamente viável a longo prazo, pois seus custos com manutenção e reparo serão menores se comparados ao asfalto convencional.

Do ponto de vista técnico, não foi possível realizar a análise comparativa entre os dois tipos de asfalto, pois não houve agregação da borracha ao agregado, fazendo com que o corpo de prova não obtivesse a resistência esperada. Por fim, pode-se concluir que o asfalto-borracha é uma grande alternativa para uso em pavimentação. Este trabalho mostrou que a incorporação de borracha triturada de pneus em pavimentação asfáltica pode ser umas das alternativas tecnicamente viáveis de reciclagem para o pneu.

\section{REFERÊNCIAS}

BERTOLLO, S. A. M.. Avaliação laboratorial de misturas asfálticas densas modificadas com borracha reciclada de pneus. Tese (Doutorado em Transportes) Universidade de São Paulo, São Carlos, 2002.

CEMPRE. Compromisso Empresarial para a Reciclagem. O mercado para reciclagem. São Paulo: CEMPRE, 2018.

DIAS, M. R.. Utilização de mistura asfáltica com borracha pelo processo da via-seca: execução de um trecho experimental urbano em Porto Alegre-RS. Dissertação (Mestrado em Engenharia Civil) Universidade Federal do Rio Grande do Sul, Porto Alegre, 2005.
ODA, S.. Análise da viabilidade técnica da utilização do ligante asfalto-borracha em obras de pavimentação. Tese (Doutorado em Engenharia de Transportes) Universidade de São Paulo, São Carlos, 2000.

SEST SENAT. Serviço Nacional de Aprendizagem do Transporte. Cerca de $\mathbf{4 5 0}$ mil toneladas de pneus são descartadas por ano no Brasil. Brasília: SEST SENAT, 2017.

SPECHT, L. P.. Avaliação de misturas asfálticas com incorporação de borracha reciclada de pneus. Tese (Doutorado em Engenharia Civil) - Universidade Federal do Rio Grande do Sul, Porto Alegre, 2004.

A CBPC - Companhia Brasileira de Produção Científica (CNPJ: 11.221.422/0001-03) detém os direitos materiais desta publicação. Os direitos referem-se à publicação do trabalho em qualquer parte do mundo, incluindo os direitos às renovações, expansões e disseminações da contribuição, bem como outros direitos subsidiários. Todos os trabalhos publicados eletronicamente poderão posteriormente ser publicados em coletâneas impressas sob coordenação da Sustenere Publishing, da Companhia Brasileira de Produção Científica e seus parceiros autorizados. Os (as) autores (as) preservam os direitos autorais, mas não têm permissão para a publicação da contribuição em outro meio, impresso ou digital, em português ou em tradução. 